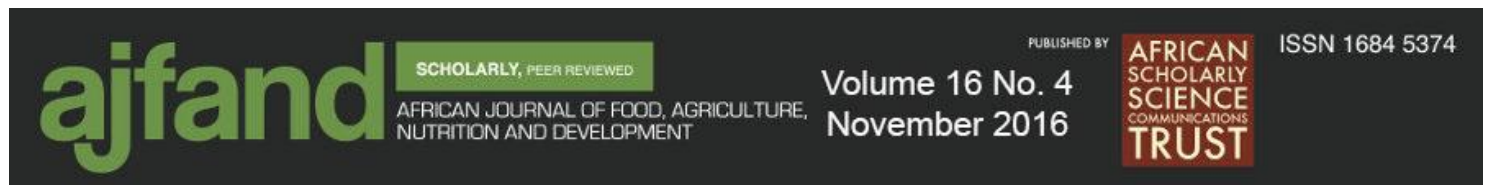

\title{
DOI: 10.18697/ajfand.76.15020
}

\section{FAST FOOD CONSUMPTION PATTERN AND BODY WEIGHT STATUS AMONG STUDENTS OF OBAFEMI AWOLOWO UNIVERSITY, ILE-IFE, NIGERIA}

\section{${\text { Bakare } \mathrm{KO}^{1 *} \text { and MF Olumakaiye }}^{2}$}

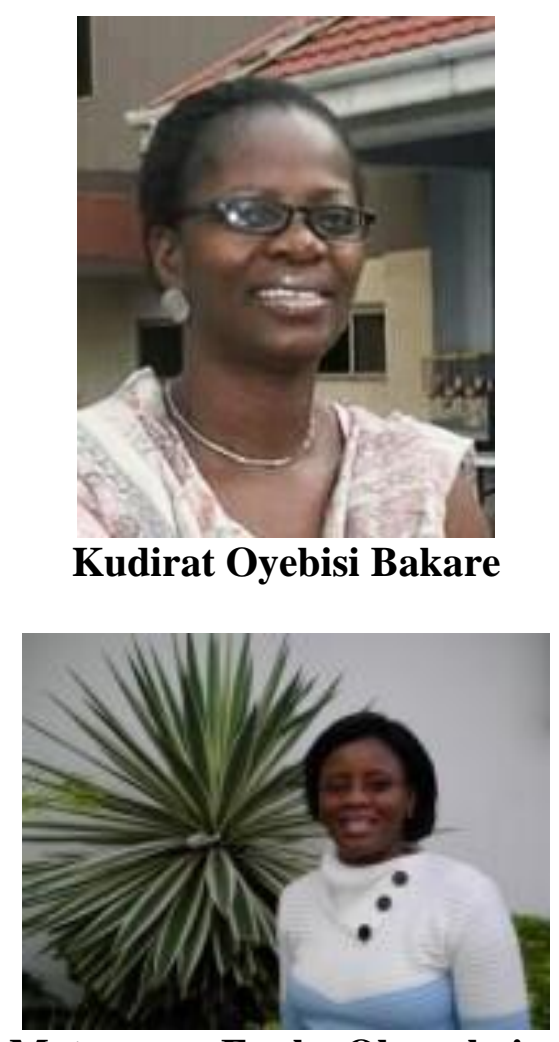

Motunrayo Funke Olumakaiye

*Corresponding author email: bissibakare@ oauife.edu.ng

${ }^{1}$ Department of Family, Nutrition and Consumer Sciences, Faculty of Agriculture Obafemi Awolowo University, Ile-Ife. Nigeria 


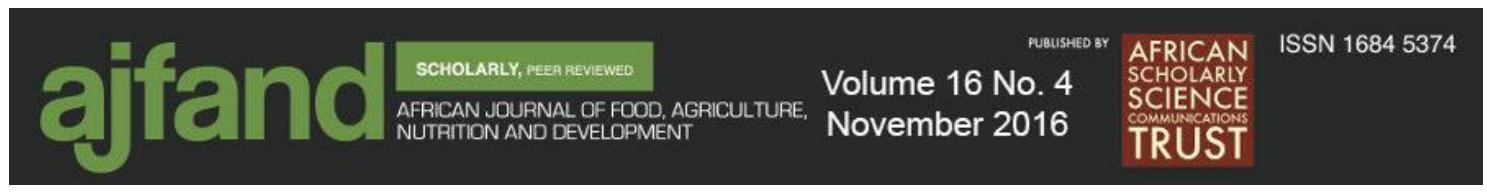

\begin{abstract}
The study assessed fast food consumption pattern (FFCP) and body weight status among the undergraduates of Obafemi Awolowo University, Ile-Ife, Nigeria, living in different halls of residence on the university campus during the Rain semester of 2011/2012 session. The study employed survey research design to give an insight into the pattern of fast food consumption and its consequent risk of obesity among undergraduates. The campus has thirteen faculties which have their pivots in science, technology, arts and social science, and nine undergraduate halls of residence. A simple random sampling technique was employed to select 40 students from each hall of nine kinds. The sum total of respondents was 360.The specific objectives were to: investigate the body weight of undergraduates using Body Mass Index (BMI), determine the gender of undergraduates who indulge most in fast food consumption, and examine the influence of fast food consumption pattern on body weight of undergraduates in Obafemi Awolowo University, Ile-Ife. The study relied on primary data which was collected through personally administered questionnaires. The respondents' weight and height were taken using a weighing scale and meter rule, respectively to determine the Body Mass Index (BMI) which was used to assess students' body weight status among the respondents. Data collected were summarized and presented using means and percentages. The hypotheses were tested using t-test to determine the significant difference in the Fast Food Consumption Pattern (FFCP) between male and female undergraduates while correlation was employed to test the significant relationship between fast food consumption (FFC) and body weight status. The findings revealed that there was a significant difference $(\mathrm{t}=$ 7.14; $\mathrm{df}=1 ; \mathrm{p}<0.05)$ between the FFC of male and female undergraduates. The study further showed from the correlation coefficient analysis that there was a significant relationship between FFC and Obesity $(r=0.47, p<0.05)$. Based on the findings, the study recommended that the university commission should postulate a compulsory general elective course on physical health and nutrition education across board to give fitness to students and teach them nutrition information and knowledge.
\end{abstract}

Key words: Overweight, Students, Obesity, Fast-food, Food consumption, Binge, BMI, University 




\section{INTRODUCTION}

Globalization has been observed to influence the production and processing of food as well as its sales, preparations and consumption and with growing relative importance of snacks, burgers, pizzas and soft drinks. Urbanization, being one of the elements of globalization is also one of the factors leading to change in lifestyles and increased income of young people. Moreover, it has been stated that demand for food is associated with the lifestyle of urban areas [1]. Fast foods are those convenient foods that are often baked and/or fried to cook and served very quickly in a restaurant. These include burger, meat pie, puff-puff, scotch egg, sausage roll, and chin-chin among others. Nigerians are getting addicted to the fast food syndrome, coupled with the avalanche of fast food restaurants that are springing up in the cities [2]. Now fast food centres are found at street corners, off the side of inter-states, airports, malls, schools, gas stations, local shopping centres, and even in hospitals [3]; it is that ubiquitous. Fast food tends to be more convenient than ever, as previous research showed that there had been a constant rise in the demand for convenience foods and snacks over a number of years $[4,5]$, as a result of increased industrialization.

For many students, the day is not complete without observing the "daily ritual" of visiting a fast food joint and most of the fast food restaurants in the cities have begun to open centres within and close to schools especially university campuses [6]. The number of meals eaten at home has reduced; lighter meals appear to be taken in place of formal meals due to the nature of work schedule of individuals [7].Fast food consumption is particularly high among young adults [8].The university years are a loop into adulthood for many young adults as this is a time for freedom and a chance to make personal lifestyle decisions. Studies have shown that diet and other health habits of university students are not optimal [9]. Typically, students fall short of recommendations for servings of whole grains, vegetables, fruits, milk, and meat, opting instead for fats, junk foods, sweets, and alcohol. This information is disturbing from a public health standpoint hence, young adulthood is the time when many health behaviours are formed and likely persist throughout life. With independence comes responsibility to make smart food choices. The young consumers visit fast food channels for fun and change [10].

Food in a globalized world is a means of life as individuals in their familiar environment and outside usual borough require food to survive and keep up proper body functioning. However, it has become a meaningful investment for business [11]. Diet affects the risk for many chronic diseases and disorders such as cardiovascular disfunction and obesity [12]. Childhood and adolescence are two key periods for the formation of lifelong dietary habits. Irregular class schedules, part - time jobs and variable homework loads can disrupt normal eating patterns among university students, leading to unhealthy habits that may be hard to break. A study on food behaviour among freshmen of public universities reported that $60 \%$ of the respondents do not have the habit of having the three meals (breakfast, lunch, and dinner) [13]. Students in institutions of higher learning often give excuses of academic rigour and low income for not having time for nutritious and varied foods. Previous research showed that male students were more likely to eat fast food than female students $[14,15]$. 
Skipping of meals was a common eating habit among urban Nigerian adolescent schoolgirls [16]. This is not surprising, as studies from several other developing countries have reported similar findings [17-20]. This is consistent with the reports of others [17, $18,21]$, where there is a strong indication that breakfast was the most frequently skipped meal of the day hence the high consumption of fast food and consequent obesity among females. Outside the fast food restaurant, fast food consumers ate Western diets, which might have stronger associations with overweight/obesity and poor dietary outcomes than fast food consumption itself due to poor nutritional knowledge [22].

It is suggested that exponential expansion of the fast food industry was associated with the outbreak and expansion of obesity in the world [23, 24, 25]. Currently, the most common measurement of obesity is by use of the Body Mass Index (BMI) scale. The $\mathrm{BMI}$ is based on the ratio of weight over height squared $\left(\mathrm{kg} / \mathrm{m}^{2}\right)$. The BMI gives a broader range of weight that may be appropriate for a specific height. According to the World Health Organisation (WHO), a BMI of $18.50-24.99 \mathrm{~kg} / \mathrm{m}^{2}$ is considered to be normal, a BMI greater than or equal to $25 \mathrm{~kg} / \mathrm{m}^{2}$ is overweight while a BMI greater than or equal to $30.00 \mathrm{~kg} / \mathrm{m}^{2}$ is considered a significant health risk due to obesity [26].Most medical sources defined a BMI of 27 or higher to be "obese". Although the BMI scale does not take into account musculature or fat distribution, it is the most convenient and presently the most widely understood measure of obesity risk [27]. The striking changes in food consumption, and profound public concern about health and obesity informed that there is a need for research to understand the pattern of fast food consumption among university students who often give excuses of time austerity due to demanding academic rigour.

\section{Ethical Considerations}

Approval to embark on the survey was sought and granted from the Directorate of Student Affairs, Obafemi Awolowo University, Ile-Ife, Nigeria.

\section{Objectives}

The main objective of the study was to assess the fast food consumption pattern and body weight status of young adults attending the campus of Obafemi Awolowo University, Ile-Ife, Nigeria. The specific objectives were to:

i. investigate the body weight of undergraduate students using Body Mass Index (BMI);

ii. determine the gender group that is most involved in fast food consumption;

iii. examine the influence of fast food consumption pattern on body weight of the students.

\section{METHODOLOGY}

The study was conducted at the Obafemi Awolowo University, Ile-Ife, Nigeria, during the Rain Semester, 2011/12 session. The campus has thirteen faculties which have their pivots in science, technology, arts and social science, and nine undergraduate halls of residence. The study relied on primary data which was collected through a personally administered questionnaire. The respondents were interviewed and their weight and height taken and recorded. The questionnaire contained 40 items ranging from socio- 


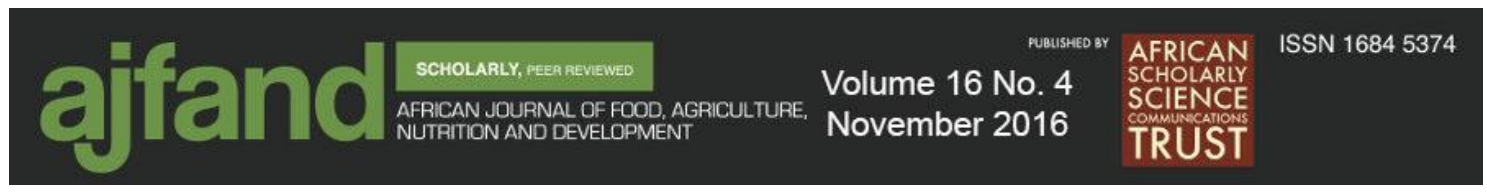

economic characteristics to one week dietary recall. The study focused only on undergraduate students because they exhibit demographics that are different from those of the postgraduate students. This is based on the observation that postgraduate students are often working class people, are married, and are more conscious of their feeding habits because of their age, exposure, and level of education. Simple random technique was used to select 40 students from each hall. The random selection was executed using interval method of selecting a student at every $5^{\text {th }}$ contact. The sum total of the respondents was 360 . The study employed survey research design to give an insight into the pattern of fast food consumption and its consequent risk of obesity among undergraduate students.

Instrument and Data Collection: The instrument used for the study was a 40-item pretested self-administered questionnaire consisting of questions relating to the sociodemographic characteristics and knowledge about fast food consumption pattern. Other items included one week diet recall, and the anthropometric measurements (height and weight) obtained through the use of a meter rule and bathroom scale, respectively, to calculate the BMI of each respondent. Descriptive (means and standard deviations) and inferential (t-test) statistics were used to respectively present and analyze the quantitative data with $5 \%$ level of significance.

\section{RESULTS}

\section{Selected Personal Characteristics of Respondents}

The total population for the study was 360 undergraduate students, which comprised 151 males and 209 females. The respondents' age was grouped into three categories of < 18years $(23.89 \%) ; 18-25$ years $(66.94 \%)$; and $\geq 26$ years $(9.16 \%)$. It was found that the students belonged to the four educational bases or study disciplines of Arts (33.89\%), Science $(28.33 \%)$, Technology (13.61\%), and Social Science $(24.17 \%)$. Length of stay of students on campus ranked as follows:<1year $(26.11 \%) ; 1-3$ years $(49.72 \%)$; and $\geq 4$ years $(24.17 \%)$. 

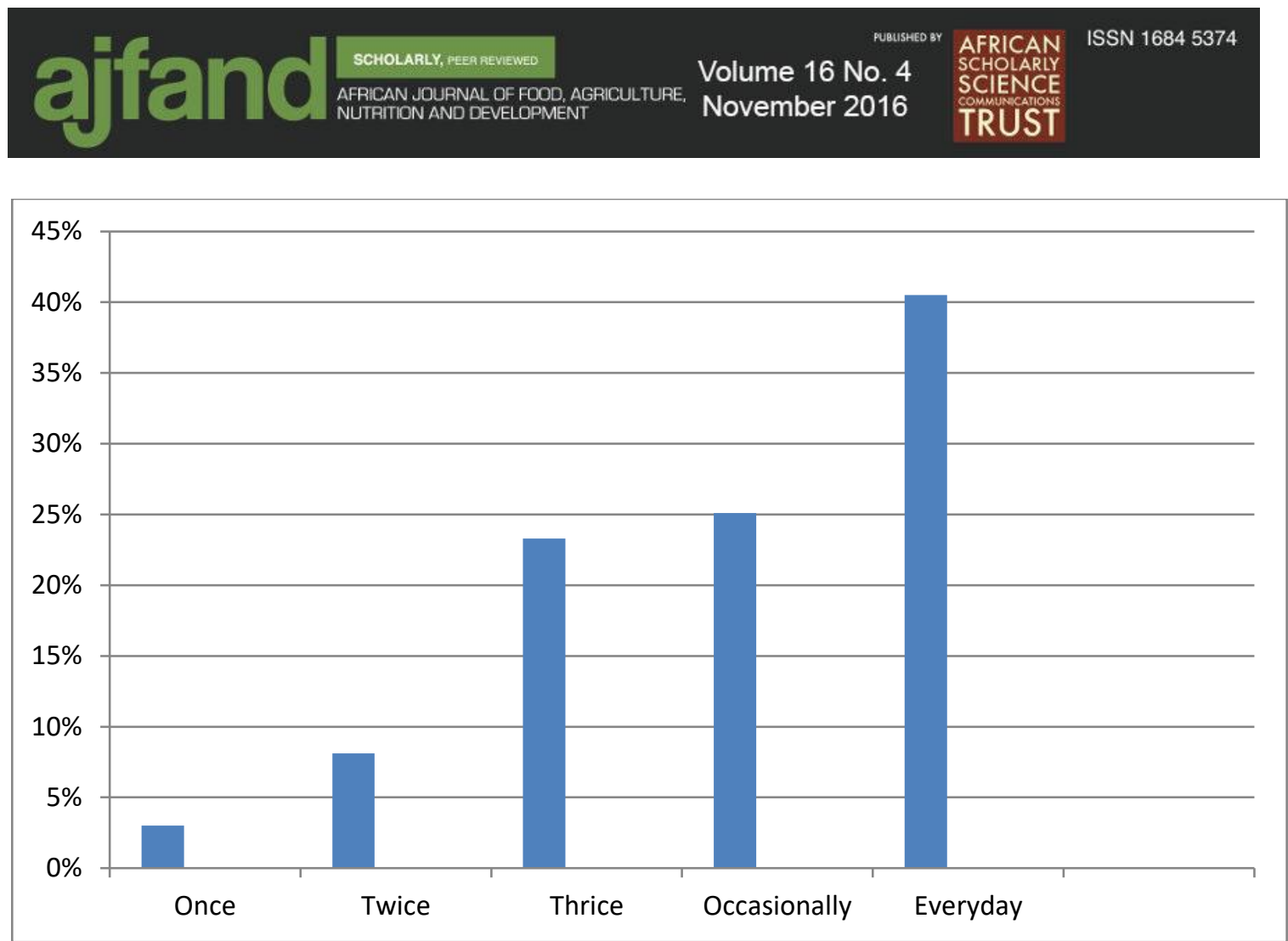

\section{Figure 1: Fast Food Consumption Pattern of Respondents using One Week Dietary Recall}

Figure 1 reveals the Fast Food Consumption Pattern (FFCP) of respondents from one week diet recall. Virtually, every student indulges in fast food consumption, once in a week $(3.0 \%)$, twice in a week $(8.1 \%)$, three times in a week $(23.3 \%)$, occasionally $(25.1 \%)$, and daily $(40.5 \%)$. None at all was an option but no student opined to it. This is an indication that every student who participated in the survey indulged in fast food consumption in the university.

\section{Perception / Attitude of Undergraduates to Fast Food Consumption}

Table 2 shows the significant differences between all the reasons identified for perception / attitude of fast food among undergraduate students except 'I know too much of it can cause obesity' and 'I don't spend too much to feed on fast food' that showed no significant importance with preference of fast food consumption.

\section{Prevalence of Obesity among Undergraduates}

Table 3 shows the distribution of prevalence of obesity among the respondents according to gender. The BMI was taken for an individual by dividing the weight in kilograms $(\mathrm{kg})$ by the height in meters $(\mathrm{m})$ squared $\left(\mathrm{kg} / \mathrm{m}^{2}\right)$. As shown in the table, $34.47 \%$ of male students had normal BMI while only $15.31 \%$ of female students had normal BMI. The 3 classes of obesity among male students $(35.76 \%)$ were lower when compared to female students (44.02\%). Overweight among female students $(38.00 \%)$ was higher than among male students (23.84\%). This implies that eating disorder (Obesity) may be higher among female students. Normal of BMI values was higher among the male students $(34.47 \%)$ while it was less among female students $(15.31 \%)$. 


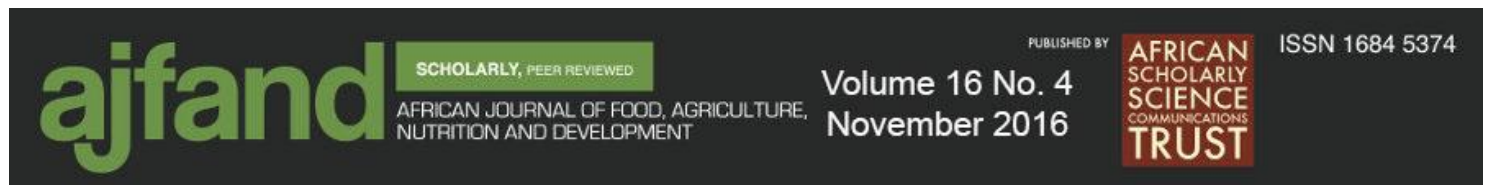

The mean BMI of the male students was $26.97 \pm 4.38$ and that of female students was

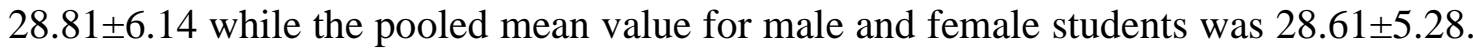
The difference between male and female students' BMI was significant $(\mathrm{P}<0.05)$.

\section{Fast Food Consumption of male and female undergraduates}

Table 4 shows that there was a significant difference $(\mathrm{t}=7.14 ; \mathrm{df}=1 ; \mathrm{p}<0.05)$ between male and female undergraduate students' fast food consumption (FFC). The results imply that more female students engage in fast food consumption than male students. It was also found that $79.9 \%$ of the female students consumed fast food when compared to $68.2 \%$ of male students. The results indicate that female students probably spend more time to study than the male students. The results may further imply that male students find it difficult to cope with snack as a replacement for main meal; it does not meet or satisfy their physiological need (hunger) as they dissipate more energy on sports and other rigorous activities. However, female students relatively eat less and can satisfy their hunger with snack consumption.

\section{Fast Food Consumption (FFC) and Obesity}

Table 5 shows that there was a significant relationship between FFC and obesity $(r=0.47$, $\mathrm{p}<0.05)$.

\section{DISCUSSION}

Results of this study showed a high prevalence of obesity among university undergraduates. The finding is in agreement with previous work that suggested Nigerians are getting addicted to the fast foods [2]. A relative good percentage of undergraduate female students were overweight and altogether the majority of university undergraduate students were overweight and obese. The results indicate that female students probably spend more time to study than the male students. The results may further imply that male students find it difficult to cope with snack as a replacement for main meal; it does not meet or satisfy their physiological need (hunger) as they dissipate more energy on sports and other rigorous activities. However, female students relatively eat less and can satisfy their hunger with snack consumption. The findings are in agreement with previous work that showed fast food consumption is particularly high among young adults [8]. The results of the findings also showed that fast food consumption pattern is higher among female students than their male counterparts. The result is at variance with the view that previous research showed that male students were more likely to eat fast food than female students $[14,15]$. The study revealed that all undergraduate students indulge in fast food consumption though to varying degrees $[1,13]$.

The study further inferred that students that are fond of fast food consumption have higher BMI, which translates into relative obesity and overweight. The finding is in agreement with previous work that showed a relationship between diet and risk of chronic diseases and conditions such as obesity and cardiovascular diseases [12]. The study further revealed that there was a significant relationship between FFCP and obesity. The results imply that fast food consumption pattern may be an important determinant of obesity occurrence among university undergraduate students. The finding is in agreement 


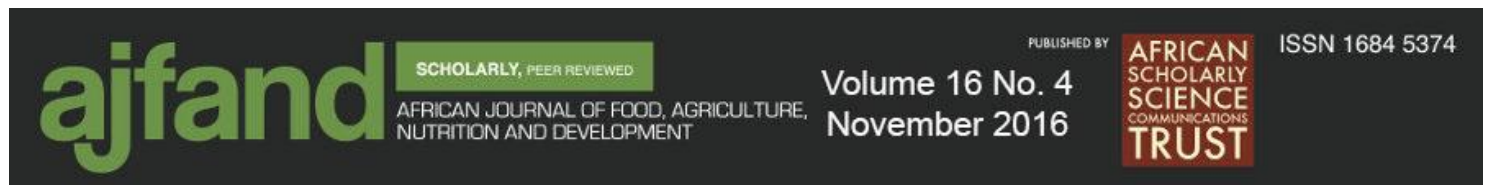

with studies that showed exponential expansion of the fast food industry to be directly related to the outbreak and expansion of global obesity [21, 22, 25].

The findings revealed that high prevalence of FFC is responsible for overweight and obesity of different classes among the undergraduates. Students often give excuses of lack of time for cooking as a result of lecture attendance and the need to study for continuous assessments and examination. Majority of undergraduate students fall into the adolescent stage while in school, while a good number of them engage in 'binge' eating or drinking. Adolescence is usually associated with uncontrolled drinking or eating caused by a disorder (binge) resulting from an unrestrained and often excessive indulgence resulting in alcoholism and/or bulimia. It was found that obesity prevalence among the respondents according to gender showed higher eating disorders among female students. This finding corroborates data from previous works [16 - 21].

\section{CONCLUSION}

The study concluded that fast food consumption is increasing among undergraduate students. The study deduced that students in institutions of higher learning have a busy schedule and have limited time for food preparation, thus prefer to get convenience food that they can just take away to their residence or eat in to save their precious time for academic work. Undergraduates found fast foods tasty as they were young adults who were transiting from adolescence. It was found from the study that fast food consumption contributed immensely to overweight and obesity among university students. Fast Food Consumption is mostly observed among female undergraduate students.

\section{RECOMMENDATION}

Based on the findings, it is recommended for the Federal and State governments to reconsider the reactivation of the cafeteria system in Nigerian universities. In addition, there should be a general elective on physical health and nutrition education to engage every student in compulsory physical exercise for fitness and equip them with necessary nutrition information and knowledge. Unhealthy citizens are a burden on governments' healthcare budgets. 


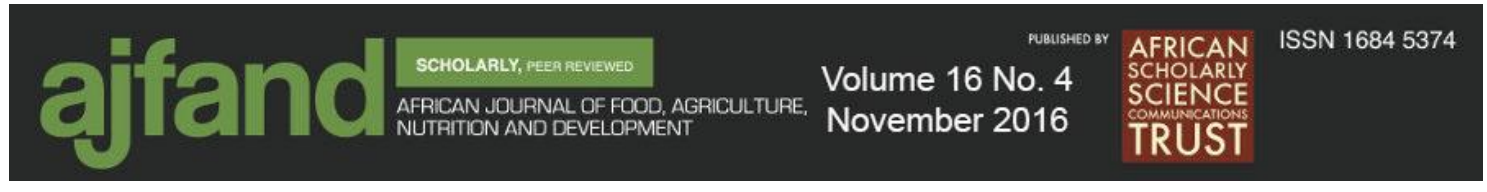

Table 1: Selected Demographic Characteristics of Respondents

\begin{tabular}{|c|c|c|c|}
\hline Characteristics & Frequency & & \\
\hline Age: & $<18$ & 86 & 23.89 \\
\hline & $18-25$ & 241 & 66.94 \\
\hline & $\geq 26$ & 33 & 09.16 \\
\hline Education Base: & Arts & 122 & 33.89 \\
\hline & Science & 102 & 28.33 \\
\hline & Technology & 49 & 13.61 \\
\hline & Social Science & 87 & 24.17 \\
\hline Sex: & Male & 209 & 58.06 \\
\hline & Female & 151 & 41.94 \\
\hline Length of stay in Sch & hool: $<1$ & 94 & 26.11 \\
\hline & $1-3$ & 179 & 49.72 \\
\hline & 4 and above & 87 & 24.17 \\
\hline Upkeep Allowance: & Low $<\# 5,000 / \mathrm{mth}$ & 156 & 43.33 \\
\hline & Medium \#5,000-\#10,000 & 123 & 34.17 \\
\hline & High $>\# 10,000$ & 81 & 22.50 \\
\hline
\end{tabular}

Study Survey, 2012 


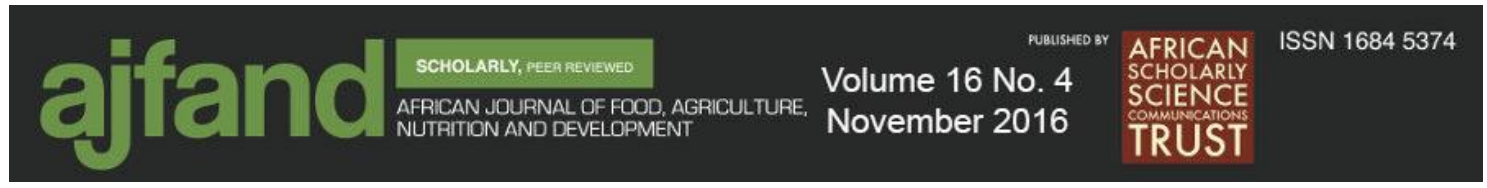

Table 2: Mean and Standard Deviation of Responses on Perception / Attitude to fast food (FF)

\section{Reasons for Preference for FFCP}

Prefer Fast food due to its taste

I feel prestigious or classy when I eat fast food

I don't spend too much to feed on fast food

I like it because it is readily available

I am not aware of any health implication from eating FF

I trust the hygiene than canteen service

I am aware that it contains more calories

I know too much of it can cause obesity

I take it out of no choice

Like it because of its convenience

Fast Food Centres (FFC) revise menus frequently

Satisfied with the price charged by FFC

FFC take cognizance of general food hints

FFCs are to blame for obesity

FFCs have added healthier options to their menu

No alternative for FF for students

Study Survey, 2012
Mean StdDevRmk

$\begin{array}{lll}4.27 & 0.79 & \text { Sig }\end{array}$

$\begin{array}{lll}4.34 & 0.82 \quad \mathrm{Sig}\end{array}$

$4.48 \quad 0.82 \quad$ Not Sig

$\begin{array}{lll}4.38 & 0.77 \quad \mathrm{Sig}\end{array}$

$\begin{array}{lll}4.32 & 0.67 & \text { Sig }\end{array}$

$\begin{array}{lll}4.61 & 0.73 \quad \text { Sig }\end{array}$

$\begin{array}{lll}4.66 & 0.67 \quad \mathrm{Sig}\end{array}$

$\begin{array}{lll}4.48 & 0.82 \quad \text { Not Sig }\end{array}$

$\begin{array}{lll}4.45 & 0.49 \quad \text { Sig }\end{array}$

$\begin{array}{lll}4.27 & 0.56 \quad \mathrm{Sig}\end{array}$

$\begin{array}{lll}4.92 & 0.81 \quad \text { Sig }\end{array}$

$\begin{array}{lll}4.18 & 0.73 \quad \text { Sig }\end{array}$

$\begin{array}{lll}4.41 & 0.33 \quad \text { Sig }\end{array}$

$\begin{array}{lll}4.62 & 0.71 \quad \text { Sig }\end{array}$

$\begin{array}{lll}4.55 & 0.84 & \mathrm{Sig}\end{array}$

$\begin{array}{lll}4.69 & 0.88 & \text { Sig }\end{array}$ 


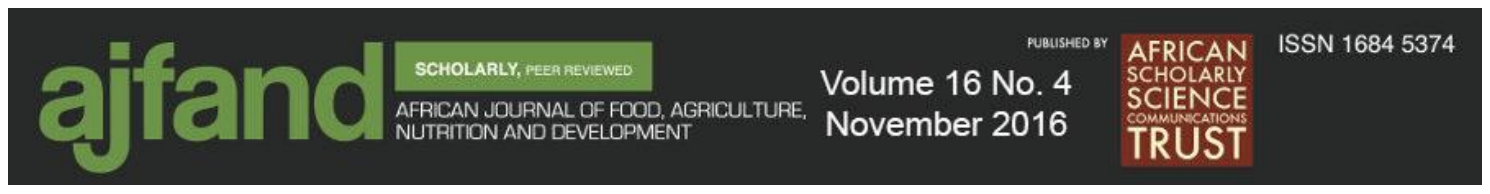

Table 3: Prevalence of Obesity among Undergraduates

Objective 1: Description of body weight of undergraduates

\begin{tabular}{lllll}
\hline Body Weight & $\left(\mathrm{BMI}=\mathrm{kg} / \mathrm{m}^{2}\right)$ & Male $(\%)$ & Female $(\%)$ & Pooled (\%) \\
\hline Underweight & $<18.5$ & $9(5.96)$ & $6(02.87)$ & $15(04.17)$ \\
Normal Weight & $18.5-24.99$ & $52(34.47)$ & $32(15.31)$ & $84(23.33)$ \\
Overweight & $25.0-29.99$ & $36(23.84)$ & $79(38.00)$ & $115(31.94)$ \\
Obese 1 & $30.0-35$ & $33(21.85)$ & $68(32.54)$ & $101(28.06)$ \\
Obese 2 & $35.1-40$ & $14(9.27)$ & $11(05.26)$ & $25(06.94)$ \\
Obese 3 & $>40$ & $07(4.64)$ & $13(06.22)$ & $20(05.56)$ \\
\hline
\end{tabular}

Study Survey, 2012

Mean BMI for male $=26.97 \pm 4.38$

Mean BMI for female $=28.81 \pm 6.14$

Pooled BMI Mean = 27.89 \pm 5.28

Table 4: Summary of t-test of difference in the FFC of male and female undergraduates

Objective 2: Difference in the sex of undergraduates that involve in fast food consumption among undergraduates

\begin{tabular}{|c|c|c|c|c|c|c|c|c|}
\hline & $\% \mathrm{FFC}$ & $\mathrm{N}$ & Mean & & SD & dftcaltcrit. & & Remark \\
\hline Male & 68.2 & 209 & 35.8 & 3.24 & 5 & 7.14 & 1.98 & $\mathrm{~S}$ \\
\hline Female & 79.9 & 151 & 38.1 & 4.13 & & & & \\
\hline
\end{tabular}

Study Survey, 2012

SD: Standard Deviation, $d f$ : degree of freedom, $N$ : Number of respondents, tcal: $t$ calculated, tcrit: $t$ tabulated or critical, S: Significant 


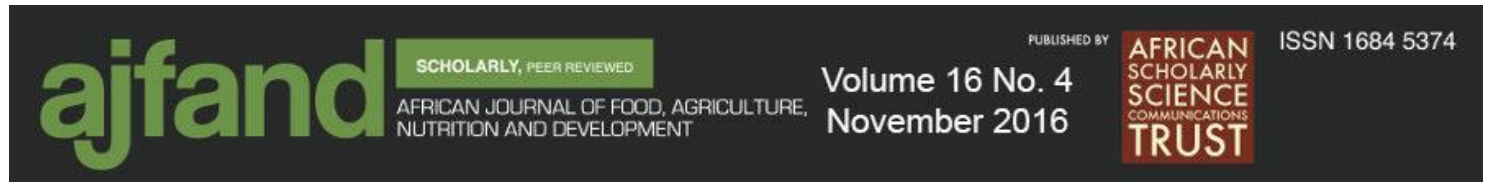

Table 5: Relationship between Fast Food Consumption Pattern (FFCP) and Obesity

Objective 3: Influence of fast food consumption on body weight of undergraduates

\begin{tabular}{lllllll}
\hline Variables & Mean & SD & N & r & P & Decision \\
\hline FFCP & 8.01 & 1.59 & 360 & $0.467^{* *}$ & 0.0001 & $\mathrm{~S}$ \\
Obesity & 74.42 & 21.17 & & & & \\
\hline Stud Survey, 2012 & & & & & & \\
\hline
\end{tabular}

Study Survey, 2012

SD: Standard Deviation, $N$ : Number of respondents, $r$ : Regression, $P: p$ value, $S$ : Significant 


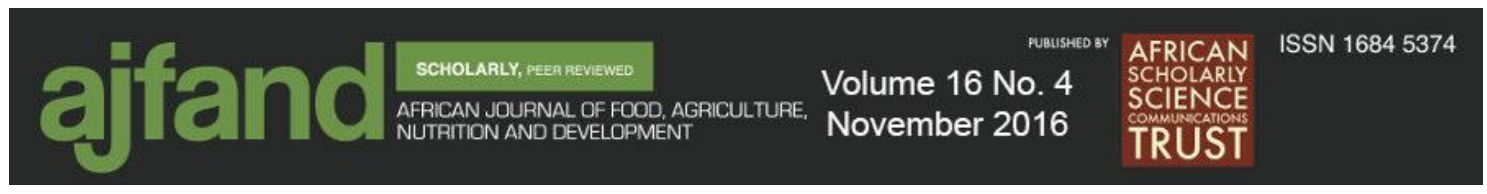

\section{REFERENCES}

1. Pingali P Westernization of Asian Diets and the transformation of food systems: Implications for science and technology". FAO. 2004.

2. Arulogun OS and MO Owolabi Fast Food Consumption Pattern among Undergraduates of the University of Ibadan, Nigeria: Implications for Nutrition Education. Journal of Agriculture, Food and Technology.2011; 1(6): 89-93.

3. Baig AK and M Saeed The Trend of Fast Food Consumption.European Journal of Economics, Finance and Administrative Sciences. 2012; 48: 78-91.

4. Traill B New Food Consumption Patterns and Product Quality in Europe and Adaptation of Agricultural Production, Food and Agriculture Organisation of the United Nations, Rome. 1994: 4-9.

5. Shimla IAS Fast Food and Home Delivery Outlets, Market Intelligence Report, Keynote, London, April. International University Centre. 2003; 10(1):143-56.

6. Aladelokun D Health freedom activists warn of the dire consequences of abandoning natural foods. Saturday Punch, June 24, 2006: A5.

7. Olumakaiye MF and KO Bakare Training of food providers for improved environmental conditions of food service outlets in urban area. Food and Nutrition Sciences, 2013;4: 99-105.

8. Guthrie J, Lin B and E Frazao Role of food prepared away from home in the American diet, 1977-78 versus 1994-96: changes and consequences. J Nutr Educ Behav. 2002; 34: 140 -50.

9. Wardlaw GM and AM Smith Contemporary Nutrition, $7^{\text {th }}$ edition. Published by Mcgraw-Hill Companies Inc. New York, NY10020. ISBN 978-0-07-1283656.2009 .

10. Goyal A and NP Singh Consumer perception about fast food in India: an Exploratory Study. British Food Journal. 2007;109(2):182-95.

11. Ragavan P Food in a globalized world - a cultural perspective. Journal of International University Centre, I.I.A.S. Shimla. 2003;10(1): 143-56.

12. Mokdad AH, Marks JM, Stroup DF and JL Gerberding Actual Causes of Death in the United States. Journal of American Medical Association. 2004; 291:1238.

13. Asano M, Fukakura N, Odachi J, Kawaraya C, Nanba A, Yasuda N and E Yamamoto Assessment of fast food usage among young generation from children to college students. Japanese Journal of Nutrition and Dietetics. 2003; 61(1): 4754. 


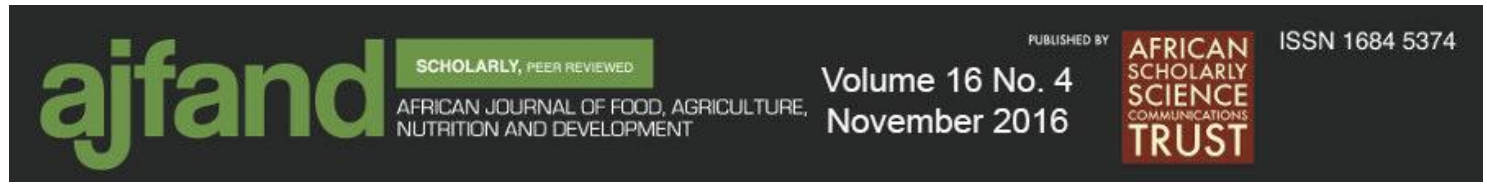

14. Kobayashi F Television viewing and fast food intake of American and Japanese college students. Nutrition and Food Science. 2010; 40 (2): 204-8.

15. Onyiriuka AN, Umoru DD and AN Ibeawuchi Weight status and eating habits of adolescent Nigerian urban secondary school girls. South African Journal of Child Health (SAJCH).2013; 7(3): 108-109.

16. Gross SM, Bronner Y, Welch C, Dewberry-Moore N and DM Paige Breakfast and lunch meal skipping patterns among fourth-grade children from selected public schools in urban, suburban, and rural Maryland. Journal of American Diet Association. 2004; 104(3):420- 423.

[http://dx.doi.org/10.1016/juda200312.014]. Accessed January 11, 2012.

17. Chin YS and NMT Mohd Eating behaviors among female adolescents in Kuantan District, Pahang, Malaysia. 2009. 8 (4):425432.[http://dx.doi.org/10.3923/pjn.2009.425.432]. Accessed January 8, 2011.

18. Thompson-McCormick JJ, Thomas JJ, Bainivnualiku A, Khan AN and AE Becker Breakfast skipping as a risk correlate of overweight and obesity in schoolgoing ethnic Fijian adolescent girls. Asia Pacific Journal of Clinical Nutrition.2010;19(3):372-382.

19. Moy FM, Gan CY and MKS Zaleha Eating patterns of school children and adolescents in Kuala Lumpur. Malaysian Journal of Nutrition. 2006: 12:1-10.

20. Shaw ME Adolescent Breakfast Skipping: An Australian Study. Adolescence 1998;33(132):851- 2008; 54(1): 21-25.

[http://dx.doi.org/10.4314/nmp.v54i1.28943]. Accessed May 22, 2009.

21. Poti JM, Duffey KJ and BM Popkin The association of fast food consumption with poor dietary outcomes and obesity among children: is it the fast food or the remainder of the diet? American Journal of Clinical Nutrition. 2004; 99: 162-71.

22. Critser G Fat Land: How Americans Became the Fattest People in the World. Houghton Mifflin, New York, NY. 2003.

23. Schlosser E Fast Food Nation. Houghton Mifflin, New York, NY. 2001; 57-74.

24. Shell ER The Hungry Gene: The Science of Fat and the Future of Thin. Atlantic Monthly, New York, NY. 2002; 5-17.

25. World Health Organisation. WHO Expert Consultation. Appropriate body-mass index for Asian populations and its implications for policy and intervention strategies. The Lancet 2004; 157-163.

26. Vague J Obesities. London, England: John Libbey. 1991; 23-60. 